\title{
Reply to 'Misconceptions on the application of biological market theory to the mycorrhizal symbiosis'
}

\begin{abstract}
Walder and van der Heijden reply The exchange of carbon for soil nutrients is thought to be the cornerstone of the arbuscular mycorrhizal (AM) symbiosis ${ }^{1,2}$. In our recent Review, we proposed that environmental conditions, functional diversity, competition for surplus resources, reciprocity and sink strength ${ }^{3}$ explain the outcome of resource exchange in the AM symbiosis. We also questioned the use of biological market theory as a universal framework to explain resource exchange in the AM symbiosis. In biological markets, interactions are viewed from an economic perspective, and the most beneficial partners are favoured in direct relation to the amount
\end{abstract} of resources received ${ }^{4-7}$.

Now, Kiers et al. ${ }^{8}$ claim that we have misunderstood biological market theory and evolutionary theory more generally, and provide six arguments challenging our view (see Supplementary Information for our point-by-point response to each argument). We do not disagree that reciprocally rewarded resource exchange exists under some conditions and with some symbiotic partners. However, as a universal model for resource exchange, this theory is too simplistic; numerous studies have shown that resources can be delivered to symbiotic partners without reciprocal rewards ${ }^{9-13}$ and even in the absence of any experienced benefit ${ }^{14,15}$. It seems that the proportionality of resource exchange is highly dependent on environmental conditions and the identity of the interacting symbionts ${ }^{11,16-18}$. Factors such as functional diversity and sink strength have a big impact on resource exchange (and its direction), and this is largely ignored in market-type exchange models.

Kiers et al. ${ }^{8}$ now provide a broader definition of the biological market theory for the AM symbiosis, expecting that individuals "have a preference, on average, for interacting with more beneficial partners".
This wider definition still does not explain why resource exchange among partners depends so strongly on environmental conditions and the identity of the interacting symbionts $^{19-21}$, and also contrasts with a recent publication by the same authors indicating that biological markets expect "immediate rewards" (see Supplementary Information for further details). We think that a broader definition of market-type resource exchange (for example, based on the whole lifespan of a species, as suggested in ref. 22) would be more widely applicable. However, such a theory would not be suitable to explain immediate regulation of resource exchange and the market concept can no longer be applied to it. Moreover, the variability included in such a broad biological market theory may be so unspecific as to have no value in understanding how AM symbiosis actually operates.

Kiers et al. ${ }^{8}$ also state that "biological market theory makes no claim on understanding (proximate) mechanisms of transfer processes". This is unfortunate because the development of a mechanistic framework would provide a platform to develop testable hypotheses, which would enable researchers to confirm or reject the biological market theory as a model to explain resource exchange in the AM symbiosis.

In our opinion, it would be useful for Kiers et al. ${ }^{8}$ to implement specific traits of the mycorrhizal symbiosis (that is, functional diversity, sink strength, exchange of surplus goods and environmental conditions) into their evolutionary models, as this would further develop the ability to explain resource exchange in the mycorrhizal symbiosis.

\footnotetext{
References

1. Smith, S. E. \& Read, D. J. Mycorrhizal Symbiosis (Academic, 2008).

2. van der Heijden, M. G. A., Martin, F. M., Selosse, M.-A. \& Sanders, I. R. New Phytol. 205, 1406-1423 (2015).
}

3. Walder, F. \& van der Heijden, M. G. A. Nature Plants 1, 15159 (2015)

4. Noë, R. \& Hammerstein, P. Behav. Ecol. Sociobiol. 35, 1-11 (1994).

5. Kiers, E. T. et al. Science 333, 880-882 (2011).

6. Wyatt, G. A. K., Kiers, E. T., Gardner, A. \& West, S. A. Evolution 68, 2603-2618 (2014)

7. Werner, G. D. A. et al. Proc. Natl Acad. Sci. USA 111, 1237-1244 (2014)

8. Kiers, E. T. et al. Nature Plants 2, 16063 (2016).

9. Olsson, P. A., Rahm, J. \& Aliasgharzad, N. FEMS Microbiol. Ecol. 72, 123-131 (2010).

10. Field, K. J. et al. Nature Commun. 3, 835 (2012).

11. Walder, F. et al. Plant Physiol. 159, 789-797 (2012).

12. Field, K. J. et al. ISME J. http://dx.doi.org/10.1038/ismej.2015.204 (2015).

13. Zhang, H., Ziegler, W., Han, X., Trumbore, S. \& Hartmann, H. Plant Soil 396, 369-380 (2015).

14. Cameron, D. D., Johnson, I., Read, D. J. \& Leake, J. R. New Phytol. 180, 176-184 (2008).

15. Veiga, R. S. L., Jansa, J., Frossard, E. \& van der Heijden, M. G. A. PLOS ONE 6, 1-10 (2011).

16. Johnson, N. C. New Phytol. 185, 631-647 (2010).

17. Ravnskov, S. \& Jakobsen, I. New Phytol. 129, 611-618 (1995).

18. Smith, S. E., Smith, F. A. \& Jakobsen, I. New Phytol. 162, 511-524 (2004).

19. Zheng, C., Ji, B., Zhang, J., Zhang, F. S. \& Bever, J. D. New Phytol. 205, 361-368 (2015).

20. Bever, J. D. New Phytol. 205, 1503-1514 (2015).

21. Lendenmann, M. et al. Mycorrhiza 21, 689-702 (2011).

22. Field, K. J. et al. New Phytol. 205, 1492-1502 (2015).

\section{Acknowledgements}

We thank Katie Field (Univ. Leeds, UK) for helpful discussion. This work was supported by Agroscope, the Swiss National Science Foundation (grant no. 143097) and the EU project OSCAR.

\section{Additional information}

Supplementary information is available online.

Marcel G. A. van der Heijden ${ }^{1,2,3 *}$ and

Florian Walder ${ }^{1 *}$

1Plant-Soil Interactions, Institute for Sustainability Sciences, Agroscope, 8046 Zürich, Switzerland, Institute of Evolutionary Biology and Environmental Studies, University of Zürich, 8057 Zürich, Switzerland,

${ }^{3}$ Plant-Microbe Interactions, Institute of Environmental Biology, Faculty of Science, Utrecht University, 3584 CH Utrecht, the Netherlands.

*e-mail: florian.walder@agroscope.admin.ch; marcel.vanderheijden@agroscope.admin.ch 